\title{
Mis-splicing of the GALNS gene resulting from deep intronic mutations as a cause of Morquio a disease
}

\author{
Anna Caciotti ${ }^{1 \dagger}$, Rodolfo Tonin ${ }^{1,2 \dagger}$, Matthew Mort ${ }^{3}$, David N. Cooper ${ }^{3}$, Serena Gasperini ${ }^{4}$, Miriam Rigoldi ${ }^{4}$, \\ Rossella Parini ${ }^{4}$, Federica Deodato ${ }^{5}$, Roberta Taurisano ${ }^{5}$, Michelina Sibilio $^{6}$, Giancarlo Parenti ${ }^{6}$, Renzo Guerrini ${ }^{1,2}$ \\ and Amelia Morrone ${ }^{1,2^{*}}$
}

\begin{abstract}
Background: Mucopolysaccharidosis-IVA (Morquio A disease) is a lysosomal disorder in which the abnormal accumulation of keratan sulfate and chondroitin-6-sulfate is consequent to mutations in the galactosamine6 -sulfatase (GALNS) gene. Since standard DNA sequencing analysis fails to detect about 16\% of GALNS mutant alleles, gross DNA rearrangement screening and uniparental disomy evaluation are required to complete the molecular diagnosis. Despite this, the second pathogenic GALNS allele generally remains unidentified in $\sim 5 \%$ of Morquio-A disease patients.

Methods: In an attempt to bridge the residual gap between clinical and molecular diagnosis, we performed an mRNA-based evaluation of three Morquio-A disease patients in whom the second mutant GALNS allele had not been identified. We also performed sequence analysis of the entire GALNS gene in two patients.

Results: Different aberrant GALNS mRNA transcripts were characterized in each patient. Analysis of these transcripts then allowed the identification, in one patient, of a disease-causing deep intronic GALNS mutation. The aberrant mRNA products identified in the other two individuals resulted in partial exon loss. Despite sequencing the entire GALNS gene region in these patients, the identity of a single underlying pathological lesion could not be unequivocally determined. We postulate that a combination of multiple variants, acting in cis, may synergise in terms of their impact on the splicing machinery.
\end{abstract}

Conclusions: We have identified GALNS variants located within deep intronic regions that have the potential to impact splicing. These findings have prompted us to incorporate mRNA analysis into our diagnostic flow procedure for the molecular analysis of Morquio A disease.

Keywords: GALNS, Morquio a disease, Mucopolysaccharidosis IVA, Deep intronic mutations, mRNA defects, Whole gene sequencing

\footnotetext{
* Correspondence: amelia.morrone@meyer.it

${ }^{\dagger}$ Anna Caciotti and Rodolfo Tonin contributed equally to this work.

'Molecular and Cell Biology Laboratory of Neurometabolic Diseases,

Paediatric Neurology Unit and Laboratories, Neuroscience Department,

Meyer Children's Hospital, Viale Pieraccini n. 24, 50139 Florence, Italy

${ }^{2}$ Dipartimento di Neuroscienze, Psicologia, Area del Farmaco e Salute del

Bambino, University of Florence, Florence, Italy

Full list of author information is available at the end of the article
}

(c) The Author(s). 2018 Open Access This article is distributed under the terms of the Creative Commons Attribution 4.0 International License (http://creativecommons.org/licenses/by/4.0/), which permits unrestricted use, distribution, and reproduction in any medium, provided you give appropriate credit to the original author(s) and the source, provide a link to the Creative Commons license, and indicate if changes were made. The Creative Commons Public Domain Dedication waiver (http://creativecommons.org/publicdomain/zero/1.0/) applies to the data made available in this article, unless otherwise stated. 


\section{Background}

Mucopolysaccharidosis IV-A or Morquio A disease (MIM \#253000] is an autosomal recessive lysosomal storage disease caused by the deficiency of $\mathrm{N}$-acetylgalactosamine-6-sulfatase (GALNS), the lysosomal enzyme responsible for the hydrolytic degradation of keratan sulfate and chondroitin-6-sulfate [1]. GALNS is encoded by the GALNS gene (NM_000512.4) which is located on chromosome 16q24.3; the gene has a length of about $50 \mathrm{~kb}$ and is organized into 14 exons [2]. The GALNS gene is alternatively spliced, with two other reported protein coding transcripts in the RefSeq database (NM_001323543.1 and NM_001323544.1) [3]. In Ensembl, 13 transcripts are reported of which four are protein coding [4].

In excess of 330 different mutations have been reported in the GALNS gene causing Morquio A disease (Human Gene Mutation Database; http://www.hgmd.org). Among them, only one solitary deep intronic mutation which created a cryptic donor splice site was previously reported [5]. Empirically, standard sequencing procedures, covering all GALNS exons and intron/exon boundaries, have failed to identify $\sim 16 \%$ of mutant alleles in patients affected by the disease $[6,7]$. However, this percentage falls to $5 \%$ when gross DNA rearrangements are also screened for [8].

Morquio A disease affects multiple organ systems but its principal features are the cartilage defects, caused by keratan sulfate accumulation, that are responsible for the typical skeletal complications including coxa valga, scoliosis, short trunk dwarfism and cervical instability [1, 9]. The diagnosis tends to be particularly challenging in attenuated Morquio A patients, with consequent increased risk for missing the correct diagnosis [1].

Several therapeutic approaches including hematopoietic stem cell transplantation, gene therapy, substrate reduction therapy, and enzyme replacement therapy (ERT) have been developed in order to try to ameliorate the disease [10-14].

Newborn screening, whether by tandem mass spectrometry on dried blood spots and/or by fluorimetric assays, has proved to be both reliable and effective in identifying most mucopolysaccharidoses, including Morquio A disease $[15,16]$. It is likely that the widespread adoption of this methodology will have a significant impact on the diagnosis of Morquio A disease $[9,17,18]$.

Here we delineate the criteria that we have found efficacious in making an early diagnosis of Morquio A disease, together with a novel screening strategy that we have devised in order to optimize the probability of obtaining a molecular diagnosis in each case. Adoption of this strategy allowed the identification of novel splicing defects in three individuals in whom only one GALNS coding region mutation had originally been found.

\section{Methods}

\section{Patients}

The clinical features, and biochemical [urinary excretion of glycosaminoglycans (GAGs) and GALNS enzyme activity] and molecular analyses of these three Morquio A disease patients are summarized in Table 1 . None of these patients has been previously reported. Based upon various empirical measurements to establish the severity of the MPS IVA phenotype [i.e. age at onset, growth/ height (based on gender) and life span; [9, 19]], Pt1 and Pt3 are affected by the severe form of the disease, whereas Pt2 may be defined as mild.

The patients' parents gave their written consent for genetic testing to be performed on a local consent form, in accordance with the Declaration of Helsinki.

\section{Biochemical assays}

Total urinary glycosaminoglycans (GAGs) were assayed as previously described [20]. Qualitative GAGs assay was performed by thin layer chromatography [21]. GALNS enzyme activity was measured from leukocytes/lymphocytes employing the fluorogenic method [22]. Beta-galactosidase (GLB1) activity was assayed in all patient samples as previously reported $[23,24]$ in order to allow exclusion of Morquio B syndrome.

It should be noted that control values for total urinary GAG evaluation can differ quite markedly between samples when the assays are performed in different centres, even though all such centres are qualified to perform the diagnostic assays. Urine keratan sulfate was found to be abundant in all samples from the three analysed patients.

\section{T-lymphocyte cell culture and treatment with cycloheximide to rescue aberrant transcripts from nonsense-mediated mRNA decay (NMD)}

Patient and control T-lymphocytes were cultured in RPMI medium supplemented with fetal bovine serum (heat inactivated for 30 mins at $56{ }^{\circ} \mathrm{C}$ ), interleukin 2 (800 U/ml), phytohemagglutinin $(2.5 \mu \mathrm{g} / \mathrm{ml})$ and antibiotics. The pool of control T-lymphocytes was separated from blood derived from 10 normal individuals. For each patient and control, lymphocytes were treated with (or without) $100 \mathrm{mg} / \mathrm{ml}$ cycloheximide (Sigma-Aldrich, Saint Louis, Missouri, USA) for 16 h. Total mRNA extraction and RT-PCR analysis are described below. Cycloheximide is used to identify cases of abnormal mRNA processing caused by mutations that generate premature termination codons (PTCs) that are then subject to NMD [25-27]. PTCs can result either from nonsense or frameshift mutations or from errors that occur during transcription or mRNA splicing [28]. Cycloheximide, being a translation elongation inhibitor, acts as a potent NMD inhibitor [26]. 
Table 1 Clinical biochemical and molecular features of MPSIVA patients

\begin{tabular}{|c|c|c|c|}
\hline Patient & 1 & 2 & 3 \\
\hline Phenotype & severe & mild & severe \\
\hline Age & 14 y $6 \mathrm{~m}$ & $16 y$ & $14 y$ \\
\hline Age at diagnosis & 3y $5 \mathrm{~m}$ & $8 y$ & $3 y$ \\
\hline Age at onset & $3 \mathrm{~m}$ & $3 y$ & $2-3 y$ \\
\hline $\begin{array}{l}\text { GALNS activity (nmol/17 h/mg } \\
\text { protein) }\end{array}$ & 0.07 (nv 40-170) & $0.2(n \vee 40-170)$ & 0 (nv 70-180) \\
\hline Genotype & c.463G $>$ A $($ ex 5)/ c.899-167A $>G$ & $\begin{array}{l}\text { c.463 G > A (ex 5)/ c.1002+ } \\
307 G>C \wedge\end{array}$ & $\begin{array}{l}\text { c.697G > A (ex 7)/ c.759- } \\
67 \mathrm{G}>\mathrm{A} \wedge\end{array}$ \\
\hline mRNA alteration & -/ r.898_899ins53 & -/ r.1003_1119del & -/ r.456_916del \\
\hline Protein alteration & p.Gly155Arg / p.Gly300Valfs*37 & $\begin{array}{l}\text { p.Gly155Arg/ } \\
\text { p.(Val335_Leu373del) }\end{array}$ & $\begin{array}{l}\text { p.Asp233Asn/ } \\
\text { p.(Lys153_Phe306del) }\end{array}$ \\
\hline Sex & female & female & male \\
\hline Parental consanguinity & no & no & no \\
\hline Height $(\mathrm{cm})$ at diagnosis & 89.5 & 121 & - \\
\hline Height $(\mathrm{cm})$ at last observation & 108.6 & 136.3 & 114.5 \\
\hline Weight (kg) & 18.2 & 26.6 & 27.5 \\
\hline Spondyloepiphyseal dysplasia & yes & yes & yes \\
\hline Chest deformity & yes & yes & yes \\
\hline Hearing loss & - & no & yes \\
\hline Corneal clouding & no & mild & no \\
\hline Coxa valga & yes & yes & yes \\
\hline Odontoid hypoplasia & yes & yes & no \\
\hline Hepatomegaly & no & yes & mild \\
\hline Cardiomyopathy & yes & no & no \\
\hline Valvular regurgitation & - & no & mitral/ tricuspid \\
\hline Mental retardation & no & no & WISC-III TIQ 89 \\
\hline Surgery (type and age) & $\begin{array}{l}\text { odontoid hypoplasia (7y), coxa valga (13y), } \\
\text { cardiomyopathy ( } 9 \mathrm{~m})\end{array}$ & $\begin{array}{l}\text { right hip (6y), left hip (7y), coxa } \\
\text { valga (10y) }\end{array}$ & coxa valga (10y) \\
\hline Urine GAGs (mg/g creatinine) & 92 (nv 48-82) & $52(\mathrm{nv} 10-63)$ & $6.6(n v 2.1-23.2)$ \\
\hline
\end{tabular}

Analysis of GALNS genomic DNA, total mRNA and CDNA synthesis

Genomic DNA was isolated from the patients' peripheral blood lymphocytes. GALNS exons were PCR amplified using oligonucleotides and reaction conditions reported previously [8].

Isolation of total mRNA from cultured lymphocytes (with and without the addition of cycloheximide) was performed with the RNeasy Mini Kit (Qiagen, Hilden, Germany) for cells and tissues and the QIAamp RNA Blood Mini kit (Qiagen, Hilden, Germany) for blood samples. RNA concentrations were determined with a Nanodrop ${ }^{\circledR}$ ND-1000 Spectrophotometer (Nanodrop technologies, Wilmington, USA). RNA integrity was checked on a $1 \%$ agarose gel. GALNS mRNA reverse transcription was carried out as previously described [29]. Nucleotide numbering of the GALNS gene corresponded to the GenBank reference sequence, NM_000512.4. Patient mutational homozygosity and/or parental carrier status were verified by targeted DNA sequence analysis of the GALNS gene in each patient's parents.

\section{Quantitative fluorescent PCR (QF-PCR) analysis and copy number variation (CNV) assays}

QF-PCR fragments corresponding to all GALNS exons were obtained both by simplex and multiplex amplifications on genomic DNAs. CNV assays were performed combining TaqMan ${ }^{\circledR}$ MGB probe chemistry with Real Time PCR instruments (Applied Biosystems ${ }^{\bullet} 7500$ Real-Time PCR) (Life Technologies Italia, Monza, Italy). The methods employed were as previously described [8].

\section{Whole GALNS gene sequencing and filtering of genetic variants}

DNA samples from patients $\mathrm{Pt} 2$ and Pt3 were prepared using the TruSeq DNA PCR-Free protocol (Illumina Inc., 
San Diego, CA, USA) and sequenced with an Illumina HiSeqX Ten generating 150 bp paired-end reads. All fragments were mapped to the hg19 human genome reference sequence using iSAAC align version 03.16.12.05. Genetic variants identified within the GALNS gene region (NM_000512.4, chr16:88880141-88,923,374) in both patients (Pt2; 144 variants and Pt3; 73 variants) were filtered in an attempt to identify the variant(s) ultimately responsible for the observed splicing defects. The first filter was employed to eliminate variants called with low confidence $(<20$ Phred quality score). A second filter was then applied to remove those variants which had been found to occur with a minor allele frequency of $>1 \%$ in the 1000 Genomes Project data (http://www.internationalgenome.org/). A location-based filter was also applied to remove those variants that were considered unlikely, based on their location, to be responsible for the splicing defect (thus, for example, the partial deletion of exon 10 in the aberrant mRNA transcript of $\mathrm{Pt} 2$ was deemed most unlikely to have been caused by a variant in exon 1). Therefore, for Pt2, this location-based filter was applied to the range chr16:88898406-88,891,277 (hg19), starting at the first base of GALNS IVS9 and extending to the last base of IVS10 (NM_000512.4). With patient Pt3, the location filter was applied to the range chr16: 8890740088,893,246 (hg19) spanning the first base of GALNS IVS4 to the last base of IVS9 [the aberrant mRNA splicing phenotype in Pt3 involved the skipping of half of exon 5, all of exons 6,7 and 8, plus half of exon 9]. Manual review of the remaining variants employed Human Splicing Finder 3.0 (HSF; http:// www.umd.be/HSF3/) to assess the potential impact of these variants on the mRNA splicing phenotype. Zygosity in the patients' parents was also employed to filter out likely non-pathogenic GALNS variants e.g. those variants found in the homozygous state in a clinically unaffected parent. The Combined Annotation-Dependent Depletion (CADD) method [30] was also used under manual review to rank the variants in terms of their potential pathogenicity; the higher the CADD score, the higher the probability that the variant is disease-causing.

\section{Results}

\section{GALNS gene and mRNA molecular analyses}

In our cohort of about 40 Morquio A patients [8, 29, 31 , the second disease-causing mutation remained uncharacterized in only three patients; the genetic analysis of these patients is reported here. Although heterozygous GALNS mutations were identified in all three patients (1,2 and 3), the second anticipated pathogenic GALNS variant was not found in any of them by standard sequencing procedures. As depicted in the flowchart (Fig. 1), the presence of large deletions/duplications was excluded by means of quantitative fluorescent-PCR and copy number variation analysis as previously described [8].

\section{GALNS gene and mRNA molecular analyses in Pt1}

Initial GALNS gene sequencing analysis of Pt1 revealed a paternally inherited heterozygous c.463G > A (p.Gly155Arg) mutation, previously described as being disease-causing [32], but no evidence of a maternally inherited lesion.

GALNS mRNA analysis, performed by RT-PCR on lymphocytes from Pt1, revealed two distinct RT-PCR products, one corresponding to the wild-type GALNS transcript, the other slightly larger. The normal RT-PCR product harboured the c.463G $>$ A (p.Gly155Arg) mutation whereas the aberrant RT-PCR product contained a 53-nucleotide sequence insertion between exons 8 and 9. When this inserted sequence was aligned to the GALNS gene sequence, it was identified as DNA sequence originating from intron 8 , which had been included as a consequence of the activation of a cryptic donor splice site. Hence, the added DNA sequence constitutes, in effect, a cryptic exon (Fig. 2f).

The targeted sequencing of GALNS intron 8 from Pt1 then revealed the mRNA defect to be due to a novel heterozygous c.899-167 A $>\mathrm{G}$ transition that serves to create an additional donor splice site (Human Splicing Finder; http://www.umd.be/HSF3/). The upstream splice acceptor site that was co-activated, thereby allowing inclusion of the 53 bp cryptic exon, was an AG dinucleotide flanked by a stretch of pyrimidines on its $5^{\prime}$ side (Additional file 1: Figure S3). The sequence of the aberrant GALNS mRNA transcript predicted a frameshift ending in a premature stop codon located at position c.953 within exon 9 (Gly300Valfs*37) (Fig. 2f; Additional file 1: Figure S3). The c.899-167 A > G lesion was also detected in the heterozygous state in the mother of Pt1.

\section{The GALNS gene and mRNA molecular analyses in Pt2 and $\mathrm{Pt} 3$}

Standard sequencing of the GALNS gene identified a single missense mutation in both Pt2 and Pt3 [p.Gly155Arg and p.Asp233Asn, respectively], but failed to identify the second disease-causing mutation in either patient. Further, RT-PCR analysis of the GALNS gene initially failed to reveal any additional RT-PCR products in Pt2 and Pt3 as compared to normal controls (data not shown). However, the same analysis performed on T-lymphocytes grown in the presence of cycloheximide revealed the presence of aberrant RT-PCR products in both patients (Fig. 2a-e).

The aberrant in-frame RT-PCR product detected in Pt2 would predict the omission of $117 \mathrm{nt}$ from exon 10 of the GALNS transcript [r.1003_1119del, p.(Val335_Leu373del)] (Fig. 2e). The aberrant splicing product detected in lymphocyte cDNA samples from Pt3 was sequenced and shown to have resulted from the 


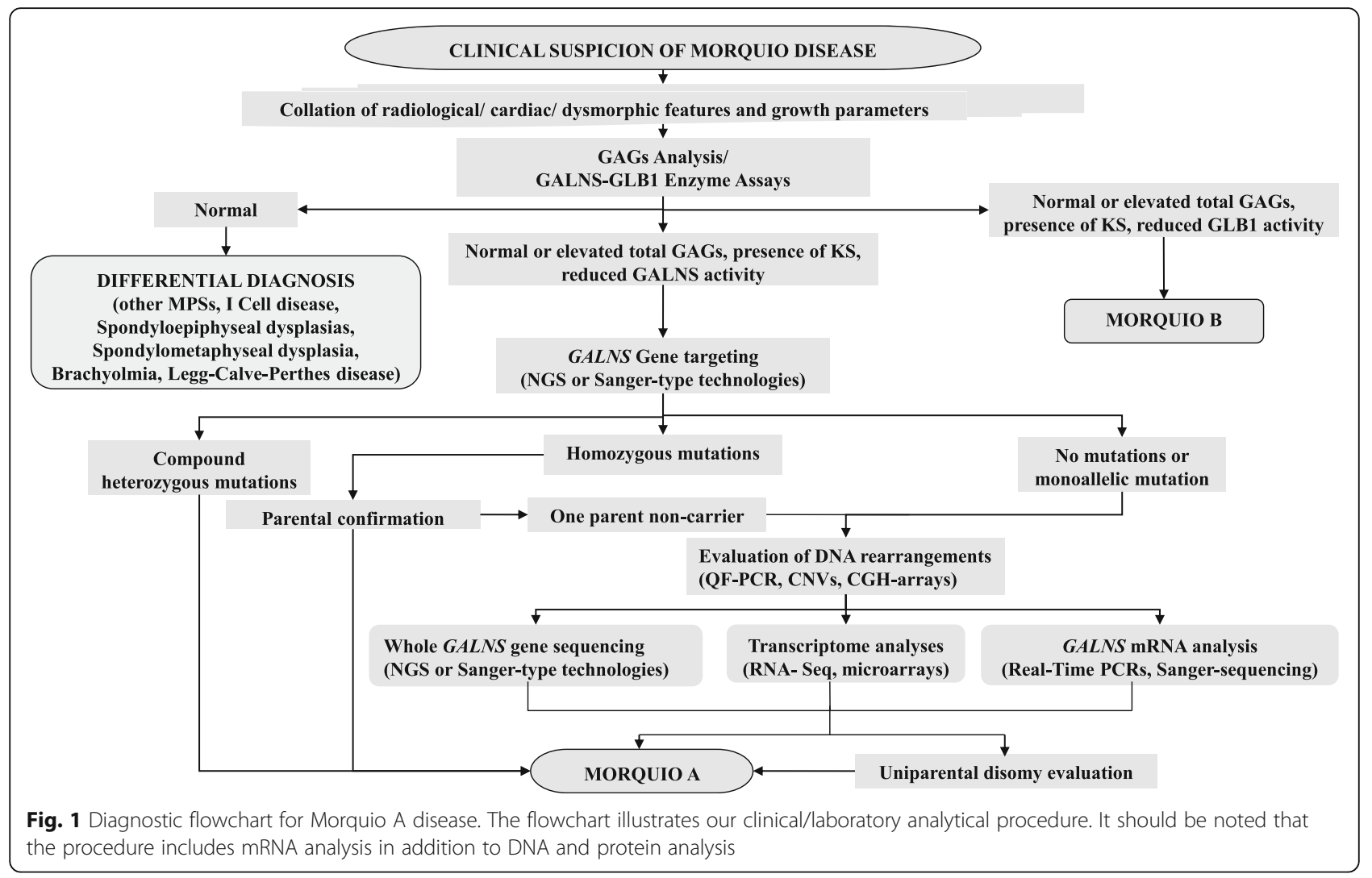

skipping of half of exon 5, all of exons 6, 7 and 8, plus half of exon 9 (r.456_916del; Fig. 2a) thereby generating a frameshift.

The GALNS mRNA evaluation performed in the father of Pt2 identified the same deletion, r.1003_1119del, that had been detected in the proband. By contrast, RT-PCR analysis revealed that the r.456_916del lesion detected in Pt3 was absent from his parents whilst two aberrant transcripts, characterized by different (albeit similar) deleted portions of GALNS exons, were detected in the mother of Pt3 (Fig. 2b and c). In addition, in both Pt3 and his father, an aberrant GALNS splicing product, that harboured the deletion of exon 9, was identified (Fig. 2d). In silico analysis suggested that both the c.697G > A (p.Asp233Asn) and c.775C > A (p.Arg259Arg) nucleotide changes could alter splicing (see HSF

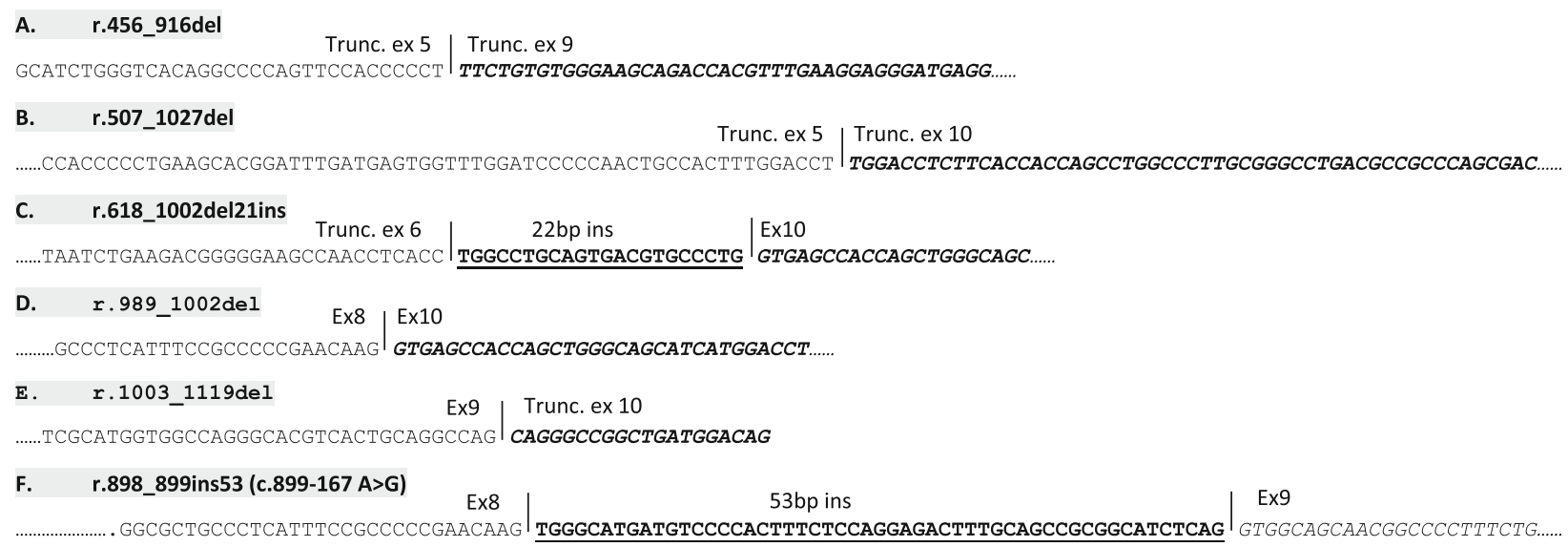

Fig. 2 Aberrant splicing products detected in Morquio A patients in the heterozygous state. The alternative GALNS CDNA (RT-PCR) products were detected in samples from: a Pt3; b, c Mother of Pt3; $\mathbf{d}$ Pt3 and his father; e Pt2; f Pt1. Ten normal controls were included alongside the three patients in the mRNA analyses in order to compare the GALNS CDNA amplification products. The control group did not show any aberrant transcripts. Del, deletion; ins, insertion; trunc, truncated; ex, exon 
predictions given in Table 2); c.697G > A (p.Asp233Asn) in Pt3 corresponds to the pathological lesion harboured by the paternal GALNS allele. Since c.775C $>$ A (p.Arg259Arg) was found in cis with the c.697G > A (p.Asp233Asn) mutation in Pt3 (i.e. it also has a paternal origin), it cannot correspond to the second pathological lesion anticipated in the GALNS gene of Pt3, despite its potential impact on splicing (Table 2). The c.697G > A (p.Asp233Asn) and c.775C > A (p.Arg259Arg) substitutions were nevertheless both identified, apparently in the homozygous state, in the aberrant splicing product lacking exon 9 that was detected in both Pt3 and his father (Fig. 2d), thereby confirming their likely role in generating this aberrant splicing product.

\section{Whole GALNS gene sequence analysis}

Among the list of GALNS gene variants identified in genomic DNA samples from Pt2 and Pt3 [143 variants in Pt2 and 69 variants in Pt3, data not shown], in silico analyses identified several potentially pathogenic variants (summarised in Table 2).

The c. $1002+307 \mathrm{G}>\mathrm{C}$ variant detected in Pt2 was predicted to result in mis-splicing (Table 2) and represents a highly plausible candidate pathological lesion (i) on the basis of its location within intron 9, (ii) because the mutant allele creates an exonic splicing enhancer (ESE) site and (iii) because it is predicted to create an exon-identity element (ccgcct) [33] and may possibly also create or abolish splice silencer motifs [34].

The c.759-67G > A variant, identified in both patient Pt3 and his mother, represents the most plausible candidate for the observed splicing defect in these individuals. Although it should be appreciated that the consequences for mRNA splicing of changes in exonic splicing regulatory elements are often unpredictable, this deep intronic variant (c.759-67G $>\mathrm{A}$ ) is predicted to abolish an existing exonic splicing silencer (ESS) motif while creating a novel ESE motif.

Intriguingly, the observed RNA splicing phenotypes differed between patient Pt3 and his mother. Thus, whereas the GALNS mRNA transcript in Pt3 harboured a $461 \mathrm{bp}$ deletion (Fig. 2a), his mother exhibited two quite distinct mis-spliced transcripts, the first harbouring a 521 bp deletion, the second an indel comprising a 385 bp deletion together with a $21 \mathrm{bp}$ insertion (Fig. 2b-c).

\section{Discussion}

The spectrum of pathological mutations and benign polymorphisms in the GALNS gene displays considerable allelic heterogeneity [HGMD Professional (Stenson et al., 2017), Exome Variant Server (http://evs.gs.washington.edu/EVS/), GALNS Mutation Database (http://galns.mutdb.org/database) etc.]. However, in approximately $16 \%$ of patients, the anticipated second disease-causing GALNS mutation cannot be unequivocally identified within the gene coding region or at the exon-intron boundaries [6, 7].

Establishing a diagnostic plan, including the requisite genetic analyses, is essential to distinguish between bona fide Morquio A disease patients and individuals with other disorders presenting with similar clinical and radiological findings $[6,9,12]$. In addition, early diagnosis is crucial for the prompt deployment of available therapies before permanent systemic lesions occur. Here, we have integrated a series of clinical and analytical tools to provide a diagnostic flow chart for Morquio A disease (Fig. 1). In the algorithm we propose, next generation sequencing (NGS) procedures

Table 2 GALNS nucleotide sequence variants with potential significance in the generation of the GALNS aberrant splicing products detected in Pt2 and Pt3

\begin{tabular}{|c|c|c|c|c|c|c|c|}
\hline $\begin{array}{l}\text { Chr: Pos } \\
\text { (GRCh37.p13) }\end{array}$ & Zygosity & $\begin{array}{l}\text { Parental } \\
\text { Zygosity }\end{array}$ & Variant Type & $\begin{array}{l}\text { Identifier (dbSNP } \\
149, \text { NCBI) }\end{array}$ & $\begin{array}{l}\text { Exon/ } \\
\text { Intron }\end{array}$ & MAF & HSF Summary/CADD score \\
\hline \multicolumn{8}{|l|}{ Pt2 } \\
\hline 16:88898099 & Heterozygous & $\begin{array}{l}\text { Paternal } \\
\text { (heterozygous) }\end{array}$ & $\begin{array}{l}\text { C.1002+ } \\
307 G>C\end{array}$ & rs866140272 & $\begin{array}{l}\text { INTRON } \\
9\end{array}$ & - & $\begin{array}{l}\text { ESE gain and alterations to various ESRs - } \\
\text { CADD } 3.002\end{array}$ \\
\hline \multicolumn{8}{|l|}{ Pt3 } \\
\hline 16:88901744 & Heterozygous & $\begin{array}{l}\text { Paternal } \\
\text { (heterozygous) }\end{array}$ & $\begin{array}{l}\text { c. } 775 C>A \\
\text { p.Arg259Arg }\end{array}$ & rs61742258 & EXON 8 & 0.002 & $\begin{array}{l}\text { Cryptic donor splice site created, ESE loss } \\
\text { and ESS gain - CADD } 14.49\end{array}$ \\
\hline 16:88901827 & Heterozygous & $\begin{array}{l}\text { Maternal } \\
\text { (heterozygous) }\end{array}$ & c.759-67G > A & rs565875595 & $\begin{array}{l}\text { INTRON } \\
7\end{array}$ & 0.001 & ESE gain and ESS loss - CADD 6.652 \\
\hline 16:88902194 & Heterozygous & $\begin{array}{l}\text { Paternal } \\
\text { (heterozygous) }\end{array}$ & $\begin{array}{l}\text { c.697G > A; } \\
\text { p.Asp233Asn }\end{array}$ & rs753051547 & EXON 7 & - & Alteration of an exonic ESE site - CADD 24.1 \\
\hline 16:88905035 & Heterozygous & $\begin{array}{l}\text { Maternal } \\
\text { (heterozygous) }\end{array}$ & c. $423-862 C>T$ & - & $\begin{array}{l}\text { INTRON } \\
4\end{array}$ & - & $\begin{array}{l}\text { Cryptic donor splice site created - CADD } \\
0.094\end{array}$ \\
\hline
\end{tabular}

- = not present in gnomAD browser beta (http://gnomad.broadinstitute.org/); MAF = minor allele frequency; ESE = exonic splicing enhancer; ESS = exonic splicing silencer; ESRs = exonic splicing regulatory sequences; HSF (Human Splicing Finder) predictions $=$ a tool which assesses the potential impact of these variants on the mRNA splicing phenotype (http://www.umd.be/HSF3/); CADD = Combined Annotation Dependent Depletion = a tool for scoring the deleteriousness of single nucleotide variants as well as insertion/deletion variants in the human genome. A CADD score of $>10$ is applied as a threshold to identify high-confidence disease-causing mutations [27] 
may be employed in two distinct analytical steps (Fig. 1). In the first, the exonic sequences and exon-intron boundaries of the gene in question are sequenced by NGS methodology (whole exome); alternatively, whole genome sequencing can be employed to sequence the entire gene region $(\sim 50 \mathrm{~kb})$. In a second step, high-throughput sequencing-based methods can be used to perform transcriptome analysis (RNA-Seq) [35], including of course, in our case, GALNS transcripts.

We have presented here the cases of three Morquio A patients in whom the second disease-causing GALNS mutation was not initially identifiable either by standard sequencing procedures or by the analysis of gross DNA rearrangements and instead had to be determined by means of RT-PCR. Aberrant GALNS mRNA splicing products were noted in all three patients. In Pt1, the deep intronic mutation c.899-167 A > G was unequivocally identified as the lesion responsible for the aberrant mRNA (including an elongated exon) and a prematurely truncated GALNS protein. Hence, this aberrant splicing event can be directly and unambiguously related to the severe clinical phenotype observed in this patient.

Mutations located within deep intronic regions, that appear capable of promoting the use of alternative natural or non-natural splicing sites, were identified by GALNS whole gene sequencing analyses of Pt2 and Pt3 samples. After following the variant prioritisation protocol described above, specific GALNS variants in Pt2 (c.1002+ $307 \mathrm{G}>\mathrm{C}$ ) and Pt3 (c.759-67G > A) were predicted to make a contribution to the clinical phenotype in these individuals by impacting mRNA splicing. These variants exhibited a very low Minor allele frequency (MAF), and were predicted to modulate splicing, particularly with respect to potential ESE and ESS sequences.

Since both of the aberrantly spliced products detected in Pt2 and Pt3 disrupt exons, the mechanism responsible for these splicing alterations cannot be precisely ascertained. Indeed, it remains possible that a particular combination of variants could have been responsible for the observed splicing defects, rather than one variant on its own. Consequently, it may be that any of the other variants detected in the patients, including the putatively non-pathogenic GALNS variants (143 variants in Pt2 and 69 variants in Pt3, post-prioritization), may have contributed to the generation of the non-physiological splicing events detected e.g. c.423-862C $>\mathrm{T}$ identified in Pt3 and his mother. It should also be appreciated that variants such as c.423-862C $>\mathrm{T}$ may disrupt canonical splice junction sequences, i.e. cryptic acceptor and donor splice sites. Thus, it may well be that it is the combination of altered canonical and non-canonical splice sites in both patients that gives rise to these unique splicing alterations.
The GALNS gene is known to be alternatively spliced, with at least three known protein coding transcripts currently annotated (NM_00512.4, NM_001323544.1 and NM_00132354.1). It is possible that these alternative transcripts were differentially expressed between Pt3 and his mother; if so, this might have led to changes in splicing factor supply and demand, which could in turn account for the differences in the observed mRNA splicing phenotype between the patient and his mother.

Owing to the difficulties inherent in interpreting this atypical type of splicing event and our veritable ignorance of splicing regulatory regions, our approach did not unequivocally identify disease-causing variants at the DNA level for Pt2 and Pt3 even after intensive DNA sequence analysis of the GALNS gene region. Additional functional studies, including the construction of expression systems that variously combine the identified candidate mis-spliced variants, would be necessary to formally confirm our hypotheses. However, for diagnostic purposes, the pathogenicity of the observed mRNA splicing defects is evidenced by: a) the absence of RT-PCR amplification, corresponding to the aberrant mRNA transcripts detected in Pt2 and Pt3 samples, in a pool of 10 normal controls both treated and untreated with cycloheximide; b) the splicing products detected in Pt2 and Pt3 differing from the 13 known GALNS physiological mRNAs, collected in the Ensembl Human Genome browser (http://www.ensembl.org/index.html). These considerations imply that the alternative GALNS mRNA splicing products detected in Pt2 and Pt3 are non-physiological, and are therefore likely to be consequent to the (hitherto unidentified) second disease-causing GALNS alleles in these Morquio A patients.

\section{Conclusions}

Morquio A disease is particularly prone to delayed diagnoses and/or misdiagnoses, owing to the difficulties inherent in the differential diagnosis of this rheumatic disease that requires specialist metabolic expertise. The addition of mRNA analysis and whole GALNS gene sequencing to this flowchart promises to help to identify those molecular causes of Morquio A disease which until now have been refractory to analysis. These analyses are likely to be particularly important for Morquio A screening programs in which the drawing up of a general diagnostic molecular plan is key to distinguishing between newborns who are carrying mutations associated with severe forms of the disease and those who are carrying mutations that are likely to give rise to milder or asymptomatic forms.

Our sequence analysis of the GALNS gene, involving gene level, genomic and RT-PCR analyses, 
suggests that although deep intronic mutations may be individually infrequent, they may be largely responsible for our occasional failure to identify GALNS disease alleles in Morquio A disease; it follows that marked improvements in our knowledge of the splicing machinery will be required before any diagnostic workflow can be regarded as being 100\% effective.

\section{Additional file}

Additional file 1 Figure S3. Sequence analysis of the aberrant mRNA transcript generated as a consequence of the c.899-167 A > G lesion identified in the GALNS gene of Pt1. A. GALNS mRNA sequence and schematic representation of the wild-type splicing event. B. Aberrant mRNA splicing resulting from the intronic c.899-167 A> G transition. (PPT $425 \mathrm{~kb}$ )

\section{Abbreviations}

ERT: Enzyme replacement therapy; ESE: Exonic splicing enhancer; ESS: Exonic splicing silencer; GAGs: Glycosaminoglycans; GALNS: N-acetylgalactosamine6-sulfatase; ISE: Intronic splicing enhancer; ISS: Intronic splicing silencers; MAF: Minor allele frequency; NGS: Next generation sequencing; NMD: Nonsense-mediated decay

\section{Acknowledgements}

We gratefully thank the AMMeC (Associazione Malattie Metaboliche e Congenite, Italia) for technical assistance. We also thank Dr. Marzia Rossato, Functional Genomic Laboratory, Department of Biotechnology, University of Verona, for the whole genome sequencing service.

\section{Funding}

BioMarin Pharmaceutical Inc. (USA) grants (2052 and 2616) funded the GALNS whole gene sequencing.

\section{Availability of data and materials}

The datasets used and/or analysed during the current study are available from the corresponding author on request.

\section{Authors' contributions}

AC, RTo and MM produced the bio-molecular and bio-informatics results. AM, RG and DNC designed the study. SG, MR, FD, RTa, RP, MS and GP provided clinical data. All authors contributed to the writing of the manuscript, and read and approved the final version.

\section{Ethics approval and consent to participate}

According to local ethical guidelines, all nucleic acid samples were obtained for storage and analysis only after the patients' family members' written informed consent had been obtained, using a form approved by the local Ethics Committee (Ethics Committee of the Meyer Hospital, Florence, Italy).

\section{Consent for publication}

The patients' family members' written informed consents contain their permission to publish patient data.

\section{Competing interests}

The authors declare that they have no competing interests.

\section{Publisher's Note}

Springer Nature remains neutral with regard to jurisdictional claims in published maps and institutional affiliations.

\section{Author details}

'Molecular and Cell Biology Laboratory of Neurometabolic Diseases, Paediatric Neurology Unit and Laboratories, Neuroscience Department, Meyer Children's Hospital, Viale Pieraccini n. 24, 50139 Florence, Italy. ${ }^{2}$ Dipartimento di Neuroscienze, Psicologia, Area del Farmaco e Salute del
Bambino, University of Florence, Florence, Italy. ${ }^{3}$ Institute of Medical Genetics, School of Medicine, Cardiff University, Cardiff, UK. ${ }^{4}$ Metabolic Unit, San Gerardo Hospital, Monza, Milan, Italy. ${ }^{5}$ Division of Metabolism, Bambino Gesù Children's Hospital, IRCCS, Rome, Italy. ${ }^{6}$ Department of Translational Medical Sciences, Section of Pediatrics, Federico II University of Naples, Naples, Italy.

Received: 11 May 2018 Accepted: 24 September 2018

Published online: 11 October 2018

\section{References}

1. Wood TC, Harvey K, Beck M, Burin MG, Chien YH, Church HJ, D'Almeida V, van Diggelen OP, Fietz M, Giugliani R et al: Diagnosing mucopolysaccharidosis IVA. J Inherit Metab Dis 2013, 36(2):293-307.

2. Nakashima Y, Tomatsu S, Hori T, Fukuda S, Sukegawa K, Kondo N, Suzuki Y, Shimozawa N, Orii T. Mucopolysaccharidosis IV a: molecular cloning of the human N-acetylgalactosamine-6-sulfatase gene (GALNS) and analysis of the 5'-flanking region. Genomics. 1994;20(1):99-104.

3. O'Leary NA, Wright MW, Brister JR, Ciufo S, Haddad D, McVeigh R, Rajput B, Robbertse B, Smith-White B, Ako-Adjei D, et al. Reference sequence (RefSeq) database at NCBI: current status, taxonomic expansion, and functional annotation. Nucleic Acids Res. 2016;44(D1):D733-45.

4. Aken BL, Achuthan P, Akanni W, Amode MR, Bernsdorff F, Bhai J, Billis K, Carvalho-Silva D, Cummins C, Clapham P, et al. Ensembl 2017. Nucleic Acids Res. 2017;45(D1):D635-42.

5. Tomatsu S, Fukuda S, Cooper A, Wraith JE, Ferreira P, Di Natale P, Tortora P, Fujimoto A, Kato Z, Yamada N et al: Fourteen novel mucopolysaccharidosis IVA producing mutations in GALNS gene. Hum Mutat 1997, 10(5):368-375.

6. Morrone A, Caciotti A, Atwood R, Davidson K, Du C, Francis-Lyon P, Harmatz $P$, Mealiffe M, Mooney S, Oron TR, et al. Morquio a syndrome-associated mutations: a review of alterations in the GALNS gene and a new locusspecific database. Hum Mutat. 2014;35(11):1271-9.

7. Tomatsu S, Montano AM, Nishioka T, Gutierrez MA, Pena OM, Tranda Firescu GG, Lopez P, Yamaguchi S, Noguchi A, Orii T. Mutation and polymorphism spectrum of the GALNS gene in mucopolysaccharidosis IVA (Morquio a). Hum Mutat. 2005:26(6):500-12.

8. Caciotti A, Tonin R, Rigoldi M, Ferri L, Catarzi S, Cavicchi C, Procopio E, Donati MA, Ficcadenti A, Fiumara A, et al. Optimizing the molecular diagnosis of GALNS: novel methods to define and characterize Morquio-a syndrome-associated mutations. Hum Mutat. 2015;36(3):357-68.

9. Hendriksz CJ, Harmatz P, Beck M, Jones S, Wood T, Lachman R, Gravance CG, Orii T, Tomatsu S. Review of clinical presentation and diagnosis of mucopolysaccharidosis IVA. Mol Genet Metab. 2013;110(1-2):54-64.

10. Tomatsu S, Averill LW, Sawamoto K, Mackenzie WG, Bober MB, Pizarro C, Goff CJ, Xie L, Orii T, Theroux M. Obstructive airway in Morquio a syndrome, the past, the present and the future. Mol Genet Metab. 2016;117(2):150-6.

11. Tomatsu S, Almeciga-Diaz CJ, Montano AM, Yabe H, Tanaka A, Dung VC, Giugliani R, Kubaski F, Mason RW, Yasuda E, et al. Therapies for the bone in mucopolysaccharidoses. Mol Genet Metab. 2015;114(2):94-109.

12. Tomatsu S, Sawamoto K, Almeciga-Diaz CJ, Shimada T, Bober MB, Chinen Y, Yabe H, Montano AM, Giugliani R, Kubaski F, et al. Impact of enzyme replacement therapy and hematopoietic stem cell transplantation in patients with Morquio a syndrome. Drug Des Devel Ther. 2015;9:1937-53.

13. Yabe H, Tanaka A, Chinen $Y$, Kato S, Sawamoto K, Yasuda E, Shintaku H, Suzuki Y, Orii T, Tomatsu S. Hematopoietic stem cell transplantation for Morquio a syndrome. Mol Genet Metab. 2016;117(2):84-94.

14. Hendriksz CJ, Parini R, AISayed MD, Raiman J, Giugliani R, Mitchell JJ, Burton BK, Guelbert N, Stewart FJ, Hughes DA, et al. Impact of long-term elosulfase alfa on activities of daily living in patients with Morquio a syndrome in an open-label, multi-center, phase 3 extension study. Mol Genet Metab. 2018; 123(2):127-34

15. Khaliq T, Sadilek M, Scott CR, Turecek F, Gelb MH. Tandem mass spectrometry for the direct assay of lysosomal enzymes in dried blood spots: application to screening newborns for mucopolysaccharidosis IVA. Clin Chem. 2011;57(1):128-31.

16. Tomatsu S, Fujii T, Fukushi M, Oguma T, Shimada T, Maeda M, Kida K, Shibata $\mathrm{Y}$, Futatsumori $\mathrm{H}$, Montano AM, et al. Newborn screening and diagnosis of mucopolysaccharidoses. Mol Genet Metab. 2013;110(1-2):42-53.

17. Kubaski F, Mason RW, Nakatomi A, Shintaku H, Xie L, van Vlies NN, Church H, Giugliani R, Kobayashi H, Yamaguchi S et al: Newborn screening for mucopolysaccharidoses: a pilot study of measurement of glycosaminoglycans by tandem mass spectrometry. J Inherit Metab Dis 2017, 40(1):151-158. 
18. Kubaski F, Osago H, Mason RW, Yamaguchi S, Kobayashi H, Tsuchiya M, Orii T, Tomatsu S. Glycosaminoglycans detection methods: applications of mass spectrometry. Mol Genet Metab. 2016.

19. Montano AM, Tomatsu S, Brusius A, Smith M, Orii T. Growth charts for patients affected with Morquio a disease. Am J Med Genet A. 2008; 146A(10):1286-95.

20. Whitley CB, Ridnour MD, Draper KA, Dutton CM, Neglia JP. Diagnostic test for mucopolysaccharidosis. I. Direct method for quantifying excessive urinary glycosaminoglycan excretion. Clin Chem. 1989;35(3):374-9.

21. Piraud M, Boyer S, Mathieu M, Maire I. Diagnosis of mucopolysaccharidoses in a clinically selected population by urinary glycosaminoglycan analysis: a study of 2,000 urine samples. Clin Chim Acta. 1993;221(1-2):171-81.

22. van Diggelen OP, Zhao H, Kleijer WJ, Janse HC, Poorthuis BJ, van Pelt J, Kamerling JP, Galjaard H: A fluorimetric enzyme assay for the diagnosis of Morquio disease type a (MPS IV a). Clin Chim Acta 1990, 187(2):131-139.

23. Caciotti A, Garman SC, Rivera-Colon Y, Procopio E, Catarzi S, Ferri L, Guido C, Martelli P, Parini R, Antuzzi D, et al. GM1 gangliosidosis and Morquio B disease: an update on genetic alterations and clinical findings. Biochim Biophys Acta. 2011;1812(7):782-90.

24. Galjaard H. Genetic metabolic diseases early diagnosis and prenatal analysis, vol. 825. Amsterdam: Elsevier/North Holland Biochemical Press; 1980.

25. Macias-Vidal J, Gort L, Lluch M, Pineda M, Coll MJ. Nonsense-mediated mRNA decay process in nine alleles of Niemann-pick type $C$ patients from Spain. Mol Genet Metab. 2009;97(1):60-4.

26. Noensie EN, Dietz HC. A strategy for disease gene identification through nonsense-mediated mRNA decay inhibition. Nat Biotechnol. 2001;19(5):434-9.

27. Usuki F, Yamashita A, Higuchi I, Ohnishi T, Shiraishi T, Osame M, Ohno S. Inhibition of nonsense-mediated mRNA decay rescues the phenotype in Ullrich's disease. Ann Neurol. 2004;55(5):740-4.

28. Kervestin S, Jacobson A. NMD: a multifaceted response to premature translational termination. Nat Rev Mol Cell Biol. 2012;13(11):700-12.

29. Carraresi L, Parini R, Filoni C, Caciotti A, Sersale G, Tomatsu S, Orlando C, Zammarchi E, Guerrini R, Donati MA, et al. GALNS gene expression profiling in Morquio a patients' fibroblasts. Clin Chim Acta. 2008;397(1-2):72-6.

30. Kircher M, Witten DM, Jain P, O'Roak BJ, Cooper GM, Shendure J. A general framework for estimating the relative pathogenicity of human genetic variants. Nat Genet. 2014:46(3):310-5.

31. Catarzi S, Giunti L, Papadia F, Gabrielli O, Guerrini R, Donati MA, Genuardi M, Morrone A. Morquio a syndrome due to maternal uniparental isodisomy of the telomeric end of chromosome 16. Mol Genet Metab. 2012;105(3):438-42.

32. Bunge S, Kleijer WJ, Tylki-Szymanska A, Steglich C, Beck M, Tomatsu S, Fukuda S, Poorthuis BJ, Czartoryska B, Orii T, et al. Identification of 31 novel mutations in the $\mathrm{N}$-acetylgalactosamine-6-sulfatase gene reveals excessive allelic heterogeneity among patients with Morquio a syndrome. Hum Mutat. 1997;10(3):223-32.

33. Zhang C, Li WH, Krainer AR, Zhang MQ. RNA landscape of evolution for optimal exon and intron discrimination. Proc Natl Acad Sci U S A. 2008; 105(15):5797-802

34. Sironi M, Menozzi G, Riva L, Cagliani R, Comi GP, Bresolin N, Giorda R, Pozzoli U. Silencer elements as possible inhibitors of pseudoexon splicing. Nucleic Acids Res. 2004;32(5):1783-91.

35. Wang Z, Gerstein M, Snyder M. RNA-Seq: a revolutionary tool for transcriptomics. Nat Rev Genet. 2009;10(1):57-63.

\section{Ready to submit your research? Choose BMC and benefit from:}

- fast, convenient online submission

- thorough peer review by experienced researchers in your field

- rapid publication on acceptance

- support for research data, including large and complex data types

- gold Open Access which fosters wider collaboration and increased citations

- maximum visibility for your research: over $100 \mathrm{M}$ website views per year

At BMC, research is always in progress.

Learn more biomedcentral.com/submissions 